\title{
Manajemen Dan Rekayasa Lalu Lintas Pasar Way Batu Kabupaten Pesisir Barat
}

\author{
${ }^{1}$ Irfan Hardiansyah, ${ }^{2}$ Iga Herdiana Purwanti Budiono, ${ }^{3}$ Yanuar Dwi \\ ${ }^{1}$ Balai Pendidikan dan Pelatihan Transportasi Darat Mempawah \\ ${ }^{2}$ Politeknik Transportasi Darat Indonesia-STTD \\ ${ }^{3}$ Politeknik Transportasi Darat Indonesia-STTD \\ Email: irfan.hardiansyah@gmail.com
}

\begin{abstract}
Abstrak
Terwujudnya pelayanan lalu lintas adalah hal yang mutlak di lakukan demi mendorong pertumbuhan ekonomi, meningkatkan kesejahteraan masyarakat yang pada akhirnya dapat membantu pembangunan di daerah. Jaringan jalan di kawasan Pasar Way Batu yang merupakan pusat perdagangan Kabupaten Pesisir Barat sangat membutuhkan pemilihan rekayasa lalu lintas terbaik dan sesuai untuk menyelesaikan permasalahan di kawasan Pasar Way Batu demi dapat mendorong pertumbuhan ekonomi di Kabupaten Pesisir Barat.Oleh sebab itu penelitian ini bertujuan untuk mengetahui Manajemen Dan Rekayasa Lalu Lintas Pasar Way Batu Kabupaten Pesisir Barat. Penelitian dalam studi ini terbatas pada analisis sistem lalu lintas dan lebih spesifik pada pengaturan bongkar muat angkutan barang, penataan parkir dan pengaturan arus masuk keluar pasar dengan pendekatan kuantitatif. Hasil penelitian menunjukkan Unjuk kerja eksisting Ruas Jalan Way Batu memiliki V/C ratio sebesar 0,71 dengan kecepatan perjalanan mobil pada arah masuk adalah 43,9 $\mathrm{km} / \mathrm{jam}$ dan kecepatan mobil pada arah keluar adalah $46,6 \mathrm{~km} / \mathrm{jam}$. Sedangkan kecepatan motor pada arah masuk adalah 33,6 km/jam dan kecepatan motor pada arah keluar adalah 29,8 km/jam. Kinerja Simpang tidak ber APILL di Pasar Way Batu memiliki kapasitas 1.149,71 smp/jam, dengan derajat kejenuhan 0,67 dan tundaan lalu lintas 48,86 det/smp. Sehingga, tingkat pelayanan pada simpang tersebut adalah B.
\end{abstract}

Kata Kunci: Manajemen, Rekayasa, Lalu Lintas, Bongkar Muat, Parkir.

\begin{abstract}
The realization of traffic services is an absolute thing to do in order to encourage economic growth, improve the welfare of the community which in turn can help development in the region. The road network in the Way Batu Market area which is the trading center of the Pesisir Barat Regency really needs the selection of the best and appropriate traffic engineering to solve problems in the Way Batu Market area in order to encourage economic growth in the Pesisir Barat Regency. And Traffic Engineering for Way Batu Market, Pesisir Barat Regency. The research in this study is limited to traffic system analysis and more specifically on the arrangement of loading and unloading of goods, parking arrangements and regulation of market entry and exit with a quantitative approach. The results showed that the existing performance of the Way Batu road section has a V/C ratio of 0.71 with a car traveling speed in the entry direction of $43.9 \mathrm{~km} / \mathrm{hour}$ and a car speed in the exit direction of $46.6 \mathrm{~km} / \mathrm{hour}$. While the motor speed in the entry direction is $33.6 \mathrm{~km} / \mathrm{hour}$ and the motor speed in the exit direction is $29.8 \mathrm{~km} / \mathrm{hour}$. The performance of the non-APILL intersection at Way Batu Market has a capacity of 1,149.71 pcu/hour, with a saturation degree of 0.67 and a traffic delay of $48.86 \mathrm{sec} / \mathrm{pcu}$. Thus, the level of service at the intersection is $B$.
\end{abstract}

Keywords: Management, Engineering, Traffic, Loading and Unloading, Parking

http://jurnal.ptdisttd.net/index.php/ipsttd/index 


\section{A. PENDAHULUAN}

Manajemen lalu lintas adalah pengelolaan dan pengendalian arus lalu lintas dengan melakukan optimalisasi penggunaan prasarana yang adauntuk memberikan kemudahan kepada lalu lintas secara efisien dalam penggunaan ruang jalan serta memperlancar system pergerakan. Hal ini berhubungan dengan kondisi arus lalu lintas dan sarana penunjangnya pada saat sekarang dan bagaimana mengorganisasikannya untuk mendapatkan penampilan yang terbaik.

Tujuan dilaksanakannya Manajemen Lalu Lntas adalah : Mendapatkan tingkat efisiensi dari pergerakan lalu lintas secara menyeluruh dengan tingkat aksesibilitas (ukuran kenyamanan) yang tinggi dengan menyeimbangkan permintaan pergerakan dengan sarana penunjang; meningkatkan tingkat keselamatan dari pengguna yang dapat diterima oleh semua pihak dan memperbaiki tingkat keselamatan tersebut sebaik mungkin; melindungi dan memperbaiki keadaan kondisi lingkungan dimana arus lalu lintas tersebut berada; dan mempromosikan penggunaan energi secara efisien.

Menurut Soebondho dan Sutanto (1998), dalam bukunya yang berjudul "Rekayasa Lalu Lintas" kapasitas jalan adalah kemampuan suatu jalan yang menerima beban lalu lintas atau jumlah kendaraan maksimal selama satu jam dengan kondisi serta arus lalu lintas tertentu. Menurut Clarkson H.O dan Gerry (1998) dalam bukunya yang berjudul "Teknik Jalan Raya", kapasitas suatu ruas jalan adalah jumlah kendaraan maksimum yang memiliki kemungkinan yang cukup untuk melewati ruas jalan tersebut dalam periode waktu tertentu dibawah kondisi jalan dan lalu lintas yang umum.

Secara administratif kewilayahan dan pemerintahan Kabupaten Pesisir Barat belum terbilang lama. Tetapi Kabupaten Pesisir Barat terus menunjukkan perkembangan dan kemajuan dengan ciri dan sifat kehidupan perkotaan. Keadaan geografis, demografis, dan sosiologis kehidupan masyarakat berkembang dengan sangat pesat sehingga memerlukan peningkatan pelayanan dan pengaturan dalam penyelenggaraanpemerintahan terutama dalam sektor transportasi.

Semakin pesatnya perkembangan dan tuntutan aspirasi kehidupan masyarakat, maka penyelenggaraan pelayanan transportasi sebagai penunjang perpindahan di Kabupaten Pesisir Barat semakin mendesak. Oleh karena itu, penyelenggaraan transportasi yang lancar dan tertib perlu diwujudkan dalam rangka menunjang berkembangnya intensitas perkotaan

Kelancaran lalu lintas pada setiap kawasan mutlak harus didukung oleh kemampuan infrastruktur dalam memenuhi permintaan yang ada. Akan tetapi, penyediaan infrastruktur tanpa dibarengi oleh rekayasa lalu lintas tidaklah akan menghasilkan kinerja lalu lintas yang optimal. Sasaran umum kebijaksanaan pemerintah dalam bidang lalu lintas dan angkutan jalan adalah menciptakan sisitem transportasi yang terpadu dan mampu mengakomodasikan mobilitas orang dan barang dengan lancer serta menunjang pertumbuhan ekonomi dan aktifitas masyarakat. Strateginya adalah dengan mengembangkan dan melaksanakan langkah - langkah perbaikan dan pengaturan lalu lintas dan angkutan jalan secara optimal.

Permasalahan-permasalahan lalu lintas saat ini sudah mulai dirasakan oleh pengguna jalan. Selain permasalahan penyediaan prasarana jalan yang tidak sebanding dengan pertambahan kendaraan, juga permasalahan seperti hambatan pada ruas, banyaknya aktifitas selain lalu lintas yang memakai badan jalan dan faktor hambatan samping juga menjadi kendala karena banyaknya aktifitas perdagangan pada beberapa ruas jalan yang dilintasi kendaraan.

Pasar Way Batu merupakan pusat perdagangan di Kabupaten Pesisir Barat. Pasar ini mempunyai tingkat aktifitas perjalanan yang tinggi. Dengan tarikan 16.692 perjalanan orang/hari yang menyebabkan tingginya pergerakan kendaraan di kawasan tersebut yang terus bertambah. 
Seiring bertambahnya jumlah penduduk di Kabupaten Pesisir Barat dan banyaknya gangguan gangguan lalu lintas muncul di jalan tersebut seperti kendaraan, dan tingginya hambatan samping seperti kendaraan bongkar muat di pinggir jalan, badan jalan yang dijadikan tempat parkir kendaraan, dan tingginya hambatan samping seperti pedagang kaki lima.

Dari kondisi tersebut, kiranya perlu dilakukan studi tentang penataan lalu lintas di Pasar Way Batu Kabupaten Pesisir Barat sebagai bahan kajian untuk pengaturan lalu lintas guna menunjang kinerja jaringan jalan sesuai peraturan dan ketentuan. Maka dari itu, perlu dilakukan penelitian dengan Judul "Manajemen Dan Rekayasa Lalu Lintas Pasar Way Batu Kabupaten Pesisir Barat". Diharapkan dengan adanya rekayasa lalu lintas di Pasar Way Batu Kabupaten Pesisir Barat dapat mengoptimalkan penggunaan prasarana yang ada, meningkatkan efisiensi pergerakan lalu lintas secara menyeluruh dengan tingkat aksesbilitas yang tinggi.

\section{B. METODE}

Desain penelitian merupakan gambatan mengenai langkah - langkah yang akan dilakukan dalam penelitian. Desain penelitian ini berawal dari masalah yang bersifat kuantitatif dan membatasi permasalahan yang ada pada rumusan masalah. Penelitian dalam studi ini terbatas pada analisis sistem lalu lintas dan lebih spesifik pada pengaturan bongkar muat angkutan barang, penataan parkir dan pengaturan arus masuk keluar pasar. Data yang dikumpulkan dalam penulisan penelitian ini dari dua jenis data, yaitu data primer dan data sekunder. Data primer adalah data yang diambil langsung melalui survey lapangan, sedangkan data sekunder adalah data yang diperoleh dari instansi atau lembaga pemerintah terkait.

\section{HASIL DAN PEMBAHASAN \\ 1. Kondisi Eksisting dan Penilaian Kinerja}

Wilayah studi penelitian ini dilakukan di Kabupaten Pesisir Barat. Penelitian ini membahas mengenai rekayasa lalu lintas kawasan Pasar Way Batu Kabupaten Pesisir Barat. Cakupan wilayah studi ini merupakan beberapa ruas dan simpang yang ada di kawasan Pasar Way Batu Kabupaten Pesisir Barat, yang memiliki banyak permasalahan akibat parkir yang masih belum teratur dan aktivitas bongkar muat angkutan barang di sekitar ruas pasar. Untuk itu perlu diketahui ruas mana saja yang bermasalah di sekitaran Pasar Way Batu untuk dilakukan penanganan. Berikut ini Gambar V.1 Peta wilayah studi kawasan Pasar Way Batu.

Dalam perhitungan kapasitas jalan diperlukan data tipe jalan, hambatan samping, tata guna lahan, proporsi arus lalu lintas, lebar efektif jalan dan jumlah penduduk yang diperoleh dari survei inventarisasi jalan. Kegiatan pasar yang terjadi di Pasar Way Batu ini dimulai dari pukul 07.00 17.00 WIB pada setiap harinya. diketahui bahwa tipe jalan pada kawasan Pasar Way Batu yaitu 2/2 UD. Ruas jalan tersebut sebenarnya memiliki lebar lebar efektif 7 meter, akan tetapi di karenakan sebagian lahan tersebut di gunakan untuk parkir selebar 2 meter, maka lebar efektif eksisting saat ini menjadi 5 meter dengan lebar per lajur $2.5 \mathrm{~m}$.

Volume lalu lintas pada ruas jalan di kawasan Pasar Kemakmuran di dapatkan dari hasil survei pencacahan lalu lintas. dapat diketahui bahwa dengan melakukan survey pencacahan lalu lintas selama 12 jam pada ruas jalan Way Batu, ruas jalan tersebut memiliki volume lalu lintas sebesar 1051,40 smp/jam. Dalam perhitungan kapasitas jalan diperlukan data tipe jalan, hambatan samping, tata guna lahan, proporsi arus lalu lintas, lebar efektif jalan dan jumlah penduduk yang diperoleh dari survei inventarisasi jalan. Dalam perhitungan kapasitas jalan dengan memperhatika data tipe jalan, hambatan samping, tata guna lahan, proporsi arus lalu lintas, lebar efektif jalan dan 
jumlah penduduk maka dapat diperoleh kapasitas pada Jalan Way Batu adalah sebesar 1461,6 smp/jam.

Perhitungan V/C ratio di dapatkan dari perhitungan volume di bagi dengan kapasitas jalan, yang mana perhitungan $\mathrm{V} / \mathrm{C}$ ratio digunakan untuk mengetahui tingkat pelayanan pada ruas jalan. Dapat diketahui bahwa ruas jalan Pasar Way Batu memiliki memiliki V/C ratio 0,71. Dengan begitu, maka Level of Service (LOS) dari ruas Jalan Way Batu adalah C. Kecepatan ruas jalan pada Kawasan Pasar Kemakmuran dapat diketahui kecepatan mobil pada arah masuk adalah 43,9 $\mathrm{km} / \mathrm{jam}$ dan kecepatan mobil pada arah keluar adalah 46,6 km/jam. Sedangkan kecepatan motor pada arah masuk adalah 33,6 km/jam dan kecepatan motor pada arah keluar adalah 29,8 km/jam.

Tingkat pelayanan ruas jalan diukur dengan cara melihat kinerja ruas jalan. Dalam menentukan tingkat pelayanan ruas jalan pada Kawasan Pasar Way Batu berdasarkan kepada Peraturan Menteri Perhubungan No. 96 Tahun 2015. Diketahui bahwa tingkat pelayanan ruas jalan pada Kawasan Pasar Way Batu. Untuk ruas jalan Pasar Way Batu dengan V/C ratio tertinggi yakni 0,71 dan mempunyai tingkat pelayanan C. Terdapat Parkir badan Jalan,Pedagang Kaki Lima dan daerah Pertokoan.

Pengolahan data simpang pada prinsipnya sama dengan ruas jalan, yaitu dengan perhitungan kapasitas simpang dan hambatan persimpanganya. Komponen kinerja persimpangan yang terdiri dari kapasitas simpang, arus jenuh, derajat kejenuhan (DS) dan tundaan lalu lintas (DT). Dalam pengkategorian ini penelitian menggunaan PM 96 tahun 2015 tentang manajemen dan rekayasa lalu lintas di jalan sebagai panduan dalam memberikan ukuran untuk menilai kinerja simpang. Berikut ini merupakan tabel V.7 Kinerja Simpang tidak ber APILL di Pasar Way Batu. Dari Tabel dibawah ini dapat dilihat kinerja eksisting simpang Pasar Way Batu dengan kapasitas yaitu 1.149,71 smp/jam, derajat kejenuhan 0,67 dan tundaan lalu lintas 48,86 det/smp. Sehingga, tingkat pelayanan pada simpang tersebut adalah B.

\section{Analisis Karakteristik Parkir}

Parkir merupakan masalah yang paling sering ditemui dalam kegiatan lalu lintas perkotaan. Parkir dapat menjadi suatu masalah yang serius apabila terdapat pada badan jalan dimana dapat mengganggu arus lalu lintas serta mengurangi kapasitas dari jalan tersebut. Seperti yang terdapat pada ruas Jalan Pasar Way Batu yang mempunyai aktivitas kegiatan yang tinggi, parkir pada badan jalan memiliki pengaruh yang sangat signifikan terhadap arus lalu lintas. Parkir di Kawasan Pasar Way Batu Kabupaten Pesisir Barat terdiri dari 1 lokasi parkir On Street . Pada parkir On Street Pasar Way Batu Pada sisi kanan merupakan tempat parkir mobil dan sepeda motor pembeli Pasar Way batu dan untuk sisi kiri merupakan tempat prosesi bongkar muat angkutan barang.

Kapasitas parkir sendiri merupakan banyaknya kendaraan yang dapat terlayani pada suatu lahan parkir selama waktu pengoperasian parkir. Untuk menghitung suatu kapasitas parkir yakni salah satunya dengan membagi antara panjang jalan untuk parkir dengan lebar ruang kaki parkir. Hasil perhitungan kapasitas ruang parkir dapat dilihat pada Tabel 1

Tabel 1

Kapasitas Ruang Parkir Pembeli Kawasan Pasar Way Batu Kabupaten Pesisir Barat

\begin{tabular}{|l|c|c|c|c|}
\hline Nama Kendaraan & $\begin{array}{c}\text { Panjang } \\
\text { Lokasi Parkir } \\
(\mathrm{m})\end{array}$ & Sudut $\left(\mathrm{x}^{0}\right)$ & $\begin{array}{c}\text { Lebar Kaki } \\
\text { Ruang } \\
\text { Parkir }\end{array}$ & Kapasitas Statis \\
\hline Motor & 30 & 90 & 0,75 & 40 \\
\hline Mobil & 70 & 45 & 3,7 & 19 \\
\hline
\end{tabular}


Dari Tabel 1 diatas dapat diketahui bahwa kapasitas ruang parkir untuk motor lebih banyak karena disusun secara berlapis dengan pola sudut parkir $90^{\circ}$. Dengan begitu kapasitas statis yang di butuhkan untuk lokasi parkir sepeda motor adalah sebanyak 40 motor, dengan lebar kaki ruang efektif mobil sebesar 0,75 meter. Dan, kapasitas ruang parkir untuk mobil adalah sebanyak 19 mobil dengan lebar kaki ruang parkir.

Volume parkir Merupakan jumlah kendaraan yang parkir pada suatu lahan parkir selama waktu tertentu. Dari pengamatan serta analisis volume parkir di dapatkan hasil sebagai berikut:

1. Jalan Way Batu Sisi Kiri Jalan, dapat diketahui bahwa volume motor pada Jalan Way Batu yang merupakan parkir pada badan jalan di sisi sebelah kiri yakni sebanyak 356 kendaraan selama jam operasi parkir 8 jam dan volume mobil pada Jalan Way Batu yang merupakan parkir pada badan jalan di sisi sebelah kiri yakni sebanyak 230 kendaraan selama jam operasi parkir 8 jam.

2. Jalan Way Batu Sisi Kanan Jalan yang khusus untuk parkit mobil pick up dan barang dapat diketahui bahwa volume mobil pick up pada Jalan Way Batu yang merupakan parkir pada badan jalan di sisi sebelah kiri yakni sebanyak 70 kendaraan selama jam operasi parkir 8 jam. Dan berikut merupakan grafik volume parkir pick up pada ruas jalan way batu bagian sisi kanan.

Akumulasi Parkir merupakan jumlah kendaraan yang diparkir di suatu tempat pada waktu tertentu. Dari analisis akumulasi parkir dapat diketahui jumlah kendaraan yang sedang berada pada suatu lahan parkir dalam waktu operasi parkir tertentu. Diketahui bahwa akumulasi volume motor tertinggi pada ruas sisi kiri jalan Pasar Way Batu yakni 16 kendaraan pada pukul 08.15 - 08.45 dengan kondisi parkir di badan jalan. Sementara itu akumulasi volume mobil tertinggi pada ruas sisi kiri jalan Pasar Way Batu yakni 12 kendaraan pada pukul 10.15 - 10.30 dengan kondisi parkir di badan jalan dan akumulasi volume mobil tertinggi pada ruas sisi kiri jalan Pasar Way Batu yakni 4 kendaraan pada pukul 10.15 - 11.30 dengan kondisi parkir di badan jalan.

Durasi Parkir merupakan rentang waktu kendaraan parkir pada suatu lokasi parkir. Dari hasil analisis survei dapat diketahui rata-rata durasi atau lamanya waktu parkir dapat dilihat pada Gambar 1.

\section{Durasi Parkir Rata-Rata (menit)}

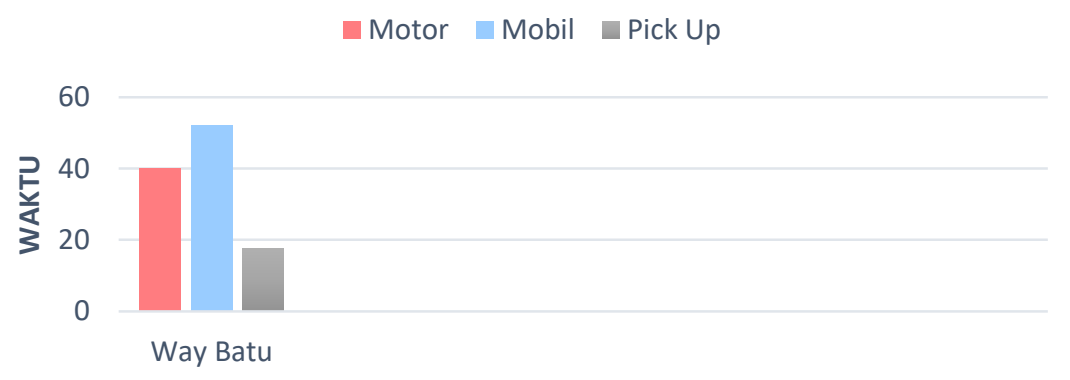

LOKASI PARKIR

\section{Gambar 1 Grafik Durasi Parkir Rata - Rata (Menit)}

Dari Gambar 1 dapat diketahui bahwasannya durasi parkir rata-rata tertinggi terjadi pada mobil, yakni 52 menit per kendaraan. Dan durasi parkir rata rata terendah terjadi pada pick up, 
yakni 18 menit per kendaraan. Dan durasi parkir rata rata tertinggi no dua terjadi pada motor, yakni 40 menit per kendaraan.

Luas lahan parkir merupakan besarnya luas lahan yang diperlukan agar mampu menampung banyaknya kendaraan yang akan parkir dalam periode waktu tertentu. Sebelum menghitung luas lahan parkir maka terlebih dahulu menghitung jumlah ruang parkir. Jumlah ruang parkir dapat dihitung dari volume parkir dikalikan dengan rata-rata durasi parkir di bagi dengan lama waktu survei, sehingga diketahui banyaknya ruang parkir yang tersedia. Selanjutnya dapat menghitung luas lahan parkir yakni dengan mengalikan jumlah ruang parkir dengan satuan ruang parkir. Berdasarkan survey patroli selama 8 jam, maka dapat diketahui jumlah kendaraan yang parkir pada ruas Jalan Way Batu pada sisi kiri jalan sebanyak 356 motor dan 230 mobil, dengan durasi rata rata parkir (jam) untuk motor selama 0,40 dan durasi rata - rata parkir (jam) untuk mobil selama 0,52. Dengan begitu, dapat diketahui jumlah ruang parkir (SRP) untuk motor sebanyak 18 kendaraan, dan jumlah ruang parkir (SRP) untuk mobil sebanyak 15 kendaraan. Untuk kendaraan pick up dapat diketahui jumlah kendaraan pick up yang parkir pada ruas Jalan Way Batu pada sisi kanan jalan sebanyak 70 kendaraan, dengan durasi rata rata parkir (jam) selama 0,47. Dengan begitu, dapat diketahui jumlah ruang parkir (SRP) untuk pick up sebanyak 4 kendaraan.

Dalam analisis ini, pembahasan akan menggunakan tingkat pertumbuhan kendaraan dan laju inflasi. Tujuan dilakukannya Pra Studi Kelayakan (Feasibility Study) tempat parkirOff Street di Pasar Way Batu adalah untuk menentukan fungsi layanan yang tepat guna, efektif, efisien, dan sesuai kebutuhan yang diperlukan dan nantinya menentukan kelayakan. Tahapan penyusunan Kompilasi Data yang dibutuhkan (data Primer dan Sekunder).

Tabel 2 Luas Lahan Parkir Yang Dibutuhkan Kondisi Eksisting Pada Kawasan Pasar Way Batu

\begin{tabular}{|c|c|c|c|c|c|c|c|}
\hline Nama & Luas Lahan & Lahan yang & Sisa & Kapasitas & Kebutuhan & Daya Muat & \\
\hline Kendaraan & yang Dibutuhkan (m2) & Digunakan (m2) & Lahan (m2) & Statis & Ruang Parkir (SRP) & Pada Visualisasi & Ket \\
\hline Mobil & 42,7 & \multirow[b]{3}{*}{610} & \multirow[b]{3}{*}{242} & 19 & 18 & 20 & Memadai \\
\hline Motor & 444,8 & & & 40 & 15 & 40 & Memadai \\
\hline Pick Up & 122,5 & & & 5 & 4 & 10 & Memadai \\
\hline
\end{tabular}

Data dalam Tabel 2 ini diperoleh dari survei patroli parkir selama 8 jam yang sudah tercantum dalam data inventarisasi parkir. Dalam perhitungan survey tersebut, mendapatkan hasil luas lahan yang di butuhkan untuk dapat menampung mobil seluas $42,7 \mathrm{~m} 2$; luas lahan yang dibutuhkan untuk menampung motor seluas 448,8 $\mathrm{m} 2$; dan luas lahan yang dibutuhkan untuk menampung Pick Up seluas 122,5m2. Data tersebut merupakan data kebutuhan parkir kendaraan pada parkir on street, yang selanjutnya akan di rencanakan untuk di pindahkan pada parkir off street dengan mengacu pada luas lahan yang dibutuhkan. Untuk saat ini lahan parkir yang tersedia pada lahan parkir pasar (off street) seluas $852 \mathrm{~m} 2$, jadi lahan yang tersisa saat ini adalah seluas $242 \mathrm{~m} 2$. Tempat parkir ini direncanakan dapat berfungsi optimal pada tahun 2019. Oleh karena itu, dengan kapasitas petak parkir yang tersedia 40 untuk, dan 25 untuk mobil, dan 10 untuk pick up. Jumlah ini diharapkan mampu menampung kendaraan pembeli, penjual dan aktivitas bongkar muat di Pasar Way Batu. 


\section{Pengaturan Waktu Operasi Angkutan}

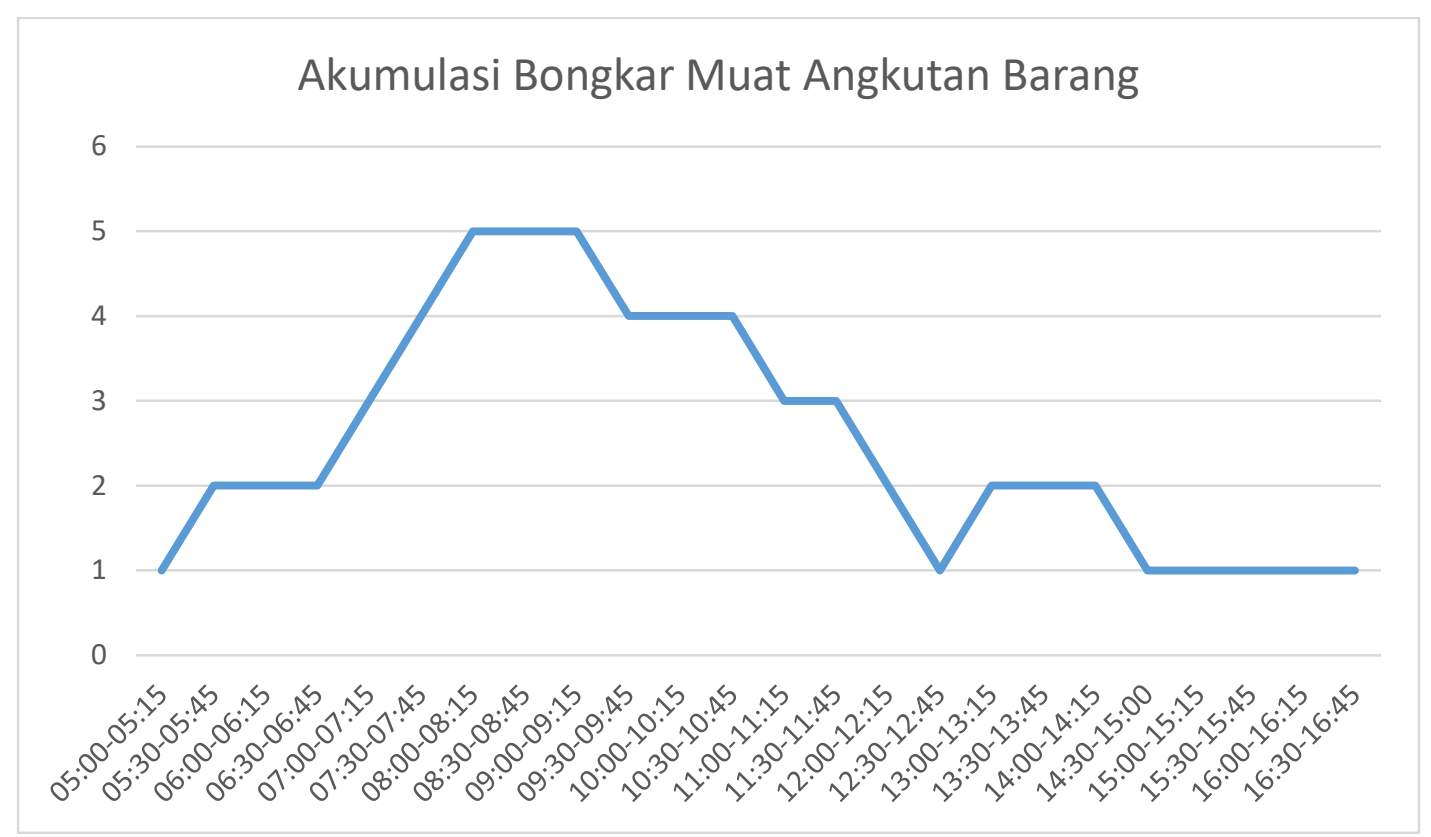

\section{Gambar V.8 Grafik Akumulasi Bongkar Muat Angkutan Barang}

Dengan melihat grafik diatas pelaksanaan bongkar muat barang terjadi pada jam sibuk lalu lintas yaitu mulai proses bongkar muat pada pukul 08.00 - 08.45 WIB yang mengurangi kinerja jalan karena pada saat proses bongkar muat kendaraan menggunakan badan jalan sehingga meyebabkan permasalahan lalu lintas yang lainnya. Pada kondisi eksisting belum tersedia lokasi bongkar muat angkutan barang yang terpusat. Oleh karena itu setelah dilakukan survei dan pengolahan data, dengan ditatanya lokasi parkir menjadi off street maka dapat ditentukan lokasi bongkar muat angkutan barang terpusat. Sedangkan untuk proses bongkar muat pada jam tidak sibuk pada siang sampai sore hari dapat dilakukan dari jam 11.15 - 17.00 WIB. dan untuk proses bongkar muat pada jam tidak sibuk pada pagi hari dapat di lakukan dari jam 05.00-06.45. Tempat bongkar muat kendaraan angkuatan barang ditempatkan pada daerah yang memiliki potensi distribusi pemindahan barang yang besar. Tempat yang tepat dalam pembuatan fasilitas bongkar muat ini adalah di samping Pasar Way Batu. Fasilitas bongkar muat ini dikhususkan kepada kendaraan angkutan barang yang melakukan distribusi pemindahan barang. Sedangkan kendaraan mobil pribadi maupun sepeda motor dilarang menggunakan fasilitas tersebut untuk parkir, dengan melakukan bongkar muat di dalam pasar pada area khusus bongkar muat yang telah disediakan.

Beberapa permasalahan yang ada pada Kawasan Pasar Kemakmuran perlu dilakukan suatu perbaikan agar dapat memberikan suatu pelayanan terhadap masyarakat berupa kenyamanan yang juga untuk meningkatkan unjuk kerja ruas serta jaringan jalan. Beberapa rekomendasi yang dapat dilakukan yakni antara lain.

a. Rekomendasi Pengalihan Parkir On Street menjadi Off Street. Rekomendasi Pengalihan Parkir On Street menjadi Off Street merupakan rekomendasi peningkatan kinerja lalu lintas dengan cara penghilangan parkir badan jalan on street menjadi parkir diluar badan jalan off street, mengatur lokasi bongkar muat yang berada di Pasar Way Batu, melakukan pemasangan rambu dilarang parkir dan dilarang berhenti di ruas jalan sisi kanan Pasar Way Batu, ruas sisi kiri jalan Pasar Way Batu, dan Ruas jalan di depan Pasar Way Batu, lalu melakukan pemasangan perambuan parkir pada lahan pasar dan menertibkan pedagang 
yang berjualan di pinggir jalan. jalan pada ruas jalan Way Batu memiliki tipe jalan 2/2 UD dengan lebar jalur efektif 7 meter, akan tetapi dikarenakan terdapat hambatan samping pada sisi kanan jalan berupa parkir selebar 1meter dan terdapat hambatan samping pada sisi kiri pasar berupa bongkar muat, maka lebar efektif pada ruas jalan Way Batu menjadi 5 meter. Dengan begitu didapatkan nilai kapasitas 1461,60 smp/jam, dan V/C ratio sebesar 0,718. Dengan begitu tingkat pelayanan pada ruas Jalan Way Batu adalah C. Setelah dilakukan peralihan parkir on street Menjadi off street maka, lebar efektif jalan kembali menjadi 7 meter. Maka, di dapatkan kembali hasil anilisis baru dengan perubahan faktor penyesuaian lebar jalur (FCw) selebar 7 meter, yakni sebesar $2610 \mathrm{smp} / \mathrm{jam}$, dan V/C ratio 0,40. Dengan begitu tingkat pelayanan pada ruas Jalan Way Batu yang baru adalah B.

b. Kinerja ruas jalan pada Kawasan Pasar Way Batu pada beberapa ruas jalan mengalami peningkatan setelah rekomendasi diterapkan. Hal tersebut dapat dilihat dari V/C ratio. Dengan tidak adanya kegiatan parkir on street, pengaturan lokasi dan waktu bongkar muat, serta tidak adanya pedagang yang berjualan di pinggir jalan sehingga kapasitas ruas jalan dapat berfungsi secara efektif, dan hal ini membuktikan bahwa kapasitas sangat berpengaruh terhadap V/C ratio ruas jalan tersebut. Berdasarkan hasil analisis diatas dapat dilihat terjadinya peningkatan kapasitas diruas Jalan Way Batu dari 1149,71 menjadi 2610 dengan persentase 55\%. Pada ruas Jalan Way Batu arah keluar, juga mengalami peningkatan kecepatan dari 29,8 km/jam menjadi 41,7 km/jam untuk motor dan mengalami penurunan kepadatan dari 35,23 smp/km menjadi 25,17 smp/km. Lalu, pada ruas Jalan Way Batu peningkatan kecepatan dan penurunan kepadatan juga terjadi pada mobil, yakni yang semula mobil memiliki kecepatan 46,6 km/jam menjadi 65,24 km/jam, dan untuk kepadatan, yang semula memiliki kepadatan $22,5 \mathrm{smp} / \mathrm{km}$ menjadi $16 \mathrm{smp} / \mathrm{km}$. Sama hal nya dengan ruas Jalan Way Batu arah masuk, juga mengalami peningkatan kecepatan dari $43,9 \mathrm{~km} / \mathrm{jam}$ menjadi $61,46 \mathrm{~km} / \mathrm{jam}$ untuk mobil dan mengalami penurunan kepadatan dari $46 \mathrm{smp} / \mathrm{km}$ menjadi $17 \mathrm{smp} / \mathrm{km}$. Lalu, pada ruas Jalan Way Batu peningkatan kecepatan dan penurunan kepadatan juga terjadi pada motor, yakni yang semula mobil memiliki kecepatan 33,6 km/jam menjadi 47,04 km/jam, dan untuk kepadatan, yang semula memiliki kepadatan 31,25 smp/km menjadi 22,32 smp/km.

\section{KESIMPULAN}

Pasar Way Batu merupakan pasar terbesar di Kabupaten Pesisir Barat dimana semua mobilitas masyarakat berpusat di Pasar Way Batu. Tingginya pergerakan lalu lintas disekitar kawasan ini menyebabkan lalu lintas semakin tidak beraturan. Selain itu tingginya hambatan samping seperti pedagang kaki lima, parkir badan jalan, dan kendaraan bongkar muat dipinggir jalan menjadi permasalahan lalu lintas di Pasar Way Batu. Unjuk kerja eksisting Ruas Jalan Way Batu memiliki V/C ratio sebesar 0,71 dengan kecepatan perjalanan mobil pada arah masuk adalah 43,9 km/jam dan kecepatan mobil pada arah keluar adalah 46,6 km/jam. Sedangkan kecepatan motor pada arah masuk adalah 33,6 km/jam dan kecepatan motor pada arah keluar adalah 29,8 $\mathrm{km} / \mathrm{jam}$. Hal ini disebabkan karena disepanjang jalan tersebut merupakan kawasan perdagangan dan jasa serta kondisi pasar yang tidak teratur sehingga volume lalu lintas yang melewati ruas jalan tersebut cukup tinggi. Kinerja Simpang tidak ber APILL di Pasar Way Batu memiliki kapasitas 1.149,71 smp/jam, dengan derajat kejenuhan 0,67 dan tundaan lalu lintas 48,86 det/smp. Sehingga, tingkat pelayanan pada simpang tersebut adalah B.

Lokasi parkir di Kawasan Pasar Way Batu Kabupaten Pesisir Barat terdiri dari 1 lokasi parkir On Street. Pada parkir On Street Pasar Way Batu Pada sisi kanan merupakan tempat parkir 
mobil dan sepeda motor pembeli Pasar Way batu dan untuk sisi kiri merupakan tempat prosesi bongkar muat angkutan barang yang saat ini akan di rencanakan untuk di pindahkan ke lahan off street yang telah di sediakan oleh pasar. Hal ini dilakukan agar kinerja ruas pada jalan Way Batu bias lebih optimal. Dikarenakan, pada ruas tersebut digunakan sebagai parkir pembeli pasar dan proses bongkar muat, sehingga lebar efektif jalan berkurang.

\section{REFERENSI}

1. Abubakar, I. (2011), Pengantar Perencanaan dan Penyelenggaraan fasilitas Parkir. Transindo Gastama Media.

2. Ahmad. (2009). Manajemen Parkir Tahun 2009. Jakarta.

3. Hasibuan, M. (2012). Manajemen Sumber Daya Manusia. Jakarta: Bumi Aksara.

4. Khisty, C. J., \& Lall, B. K., (2003). Dasar-Dasar Rekayasa Transportasi. Jilid 1, Edisi Ketiga, Jakarta: Penerbit Erlangga.

5. Kelompok PKL Kabupaten Pesisir Barat. (2018). Laporan Umum Taruna Sekolah Tinggi Transportasi Darat Program Diploma III Lalu Lintas dan AngKutan Jalan, Pola Umum Lalu Lintas dan Angkutan Darat di Wilayah Studi Kabupaten Pesisir Barat dan Identifikasi Permasalahannya

6. Sulastri, L. (2014). Manajemen Sebuah Pengantar (Sejarah, Tokoh, Teori dan Praktik). Bandung: La Goods Publishing.

7. Tamin, O. Z., (2008). Perencanaan, Permodelan \& Rekayasa Transportasi, Bandung: ITB Publisher.

8. Warpani, P.S. (2002). Pengelolaan Lalu Lintas dan Angkutan Jalan 2002. Bandung: ITB Publisher.

9. Undang - undang Nomor 22 Tahun 2009 tentang Lalu Lintas dan Angkutan Jalan, Departemen Perhubungan, Jakarta.

10. Undang-Undang Nomor 34 Tahun 2006 tentang Jalan.

11. Peraturan Pemerintah Nomor 79 Tahun 2013 tentang Jaringan Lalu Lintas Dan Angkutan Jalan.

12. Peraturan Menteri Nomor 96 Tahun 2015 Tentang pedoman pelaksanaan kegiatan manajemen dan rekayasa lalu lintas, Departemen Perhubungan , Jakarta.

13. Keputusan Direktur Jendral Bina Marga Nomor 22.2/KPTS/Db/2012.

14. Keputusan Direktur Jendral Perhubungan Darat Nomor AJ 401/1/8.

15. Manual Kapasitas Jalan Indoneesia Tahun 1997, Jakarta., 2005, Prinsip-prinsip Statistik Untuk Teknik dan Sains Tahun 2005, Jakarta. 